\title{
Trickle-Down Consumption in a Country with High Income Inequality: Evidence from Mexico
}

\author{
Daniel González Olivares and Mauricio Ramírez Grajeda*
}

Departamento de Métodos Cuantitativos, CUCEA, Universidad de Guadalajara.

\begin{abstract}
Can consumption inequality in Mexico be linked to the existence of a systematic relationship between the expenditure of top income households and that of households with lower incomes? In this paper we use a pseudopanel data set with state year variations in income and consumption to explain the idea of trickle-down consumption. For the analysis, we use the National Survey on Household Income and Expenditure (ENIGH) and we show, for the period 1992-2010, that growing income inequality in the country is intrinsically related to changes in consumption by middle-income households. In the results, we find that a 10 percent increase in income for rich households, increases the consumption of middle-income households by 1.57 percent. Also, applying a counterfactual exploratory analysis, we find that middle-income households could have saved around 20 percent more, if their income had grown at the same rate as that of rich households.
\end{abstract}

Keywords: Trickle-Down Consumption, Pseudo-Panels, Mexico, Income and Consumption Inequality.

\section{INTRODUCTION}

Traditionally, the idea of any association between the spending on consumption by one individual and that of others was completely ignored by economic models. However, it has now become an everyday topic. In the United States, for example, in spite of rather poor growth in median family earnings over the past 30 years 1 , the average size of newly constructed houses has more than doubled2. The discrepancy was originally explained by Frank et al. (2014) arguing that increased expenditure by some people almost always leads others just below them on the income scale to spend more as well. The authors refer to this behavior by using the term expenditure cascade and was used to explain the recent growth of income inequality in the country.

Following the lead of these scholars, Bertrand and Morse (2016) generalized the idea and claimed that middle-income households that are surrounded by higher income and consumption households, also consume a larger share of their current income. In their work, they coined the term trickledown consumption and showed that higher spending, bankruptcy and self-reported financial distress, all increase if you live in a community with higher income inequality, compared to another with lower income inequality.

*Address correspondence to this author at Departamento de Métodos Cuantitativos, CUCEA, Universidad de Guadalajara.;

\footnotetext{
${ }^{1}$ Source: U.S. Census Bureau, American Community Survey.

${ }^{2}$ Median house size growth:

http://www.census.gov/const/C25Ann/sftotalmedavgsqft.pdf.
}

If this is true for the United States, as the authors claim, what would the situation be like in a country with an even higher level of income inequality, like Mexico? Would the connections to increased spending be stronger? And if so, what would the determinants be?

In this paper, we address these questions and try to replicate Bertrand's idea for the Mexican economy. In our analysis, however, to make up for a shortage of data, we created our own micro panel data set, by averaging groups of observations sharing the same characteristics into one synthetic observation that could be followed over time. This synthetic observation is called pseudo-household and the rough data for the analysis is taken from the National Survey on Household Income and Expenditure (ENIGH) for the period 19922010.

It is well known that for the last 30 years, Mexico has been characterized as one of the most unequal countries in the Latin American region. During these years, a large number of articles have tried to explain the dynamics and the determinants of inequality. Also, many international institutions have carried out studies in which they recommend steps Mexico should take in order to overcome such a problematic situation but, even so, the inequality is still strongly present.

According to The World Bank (see Table 1), Mexico has maintained its position among the top 20 most unequal countries worldwide with a GINI index always above 40 points. If we use a compound annual growth rate (CAGR) from 1998 to 2016, it is easy to see that on average Mexico has only improved a poor 0.64 percent every year. For the Latin American region, Brazil is at the top of the list, and Peru has shown the largest improvement in terms of inequality, passing from the fourth position all the way dawn to the thirteenth. 
Table 1. GINI Index 1998-2017 and Compound Annual Growth Rate for Some Latin American Countries.

\begin{tabular}{|c|c|c|c|c|c|c|}
\hline Country & Code & GINI 1998 & Position 1998 & GINI 2016 & Position 2016 & CAGR (\%) \\
\hline Panama & PAN & 57.5 & 2 & 50.4 & 4 & $-0.73 \%$ \\
\hline Paraguay & PRY & 54.6 & 41 & 47.9 & 7 & $-0.77 \%$ \\
\hline Ecuador & $\mathrm{ECU}$ & 49.7 & 12 & 45 & 9 & $-0.55 \%$ \\
\hline Mexico & MEX & 48.7 & 14 & 43.4 & 15 & $-0.64 \%$ \\
\hline Argentina & ARG & 50.7 & 9 & 42.4 & 17 & $-0.99 \%$ \\
\hline
\end{tabular}

Source: GINI index (World Bank estimate).

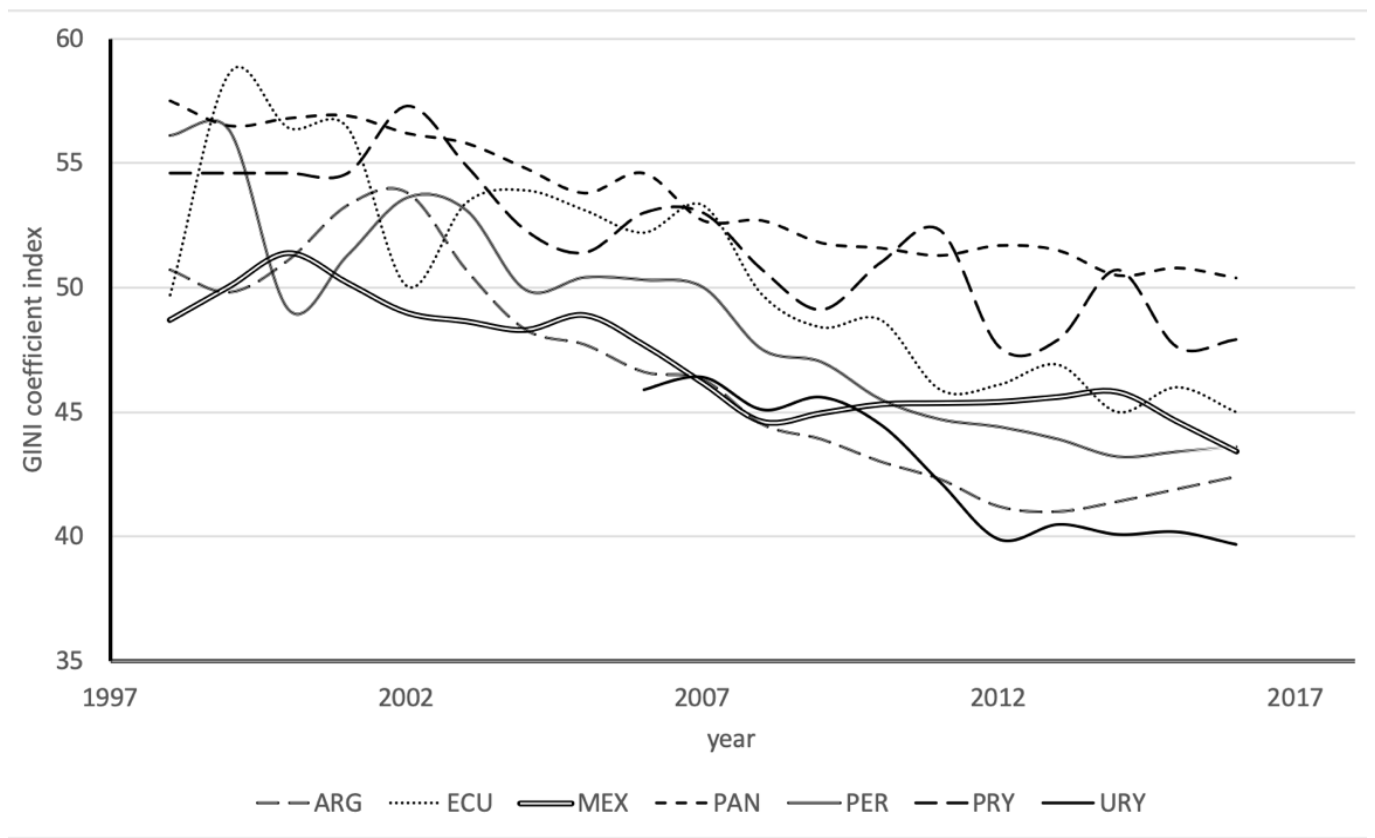

Fig. (1). GINI coefficient index for some Latin American countries (1998 - 2016).

Source: GINI index (World Bank estimate).

Looking at the long-run trend of the index, Fig. (1) also presents data for some Latin American countries. As we can see, while Uruguay shows the lowest GINI coefficient in the period, it basically did not change over time. Peru, on the contrary, showed an important improvement, passing from around 56 points in 1998 to 43 points in 2017. Mexico experienced very little progress in resolving its income inequality from 1998 onwards.

There is a great variety of literature that tries to explain income inequality in Mexico. Some studies try to explain only its dynamics (Esquivel (2008)), while others analyze its relationship to savings. For example, Attanasio and Székely (1998) characterize household's saving behavior in terms of changes in the distribution of income. The main goal of their research is to present a clearer picture of savings in Mexico, and to assess the desirability and effectiveness of polices design to stimulate private saving. To this end, they consider the national survey on household expenditure and consumption for the years 1984, 1989, 1992, 1994 and 1996, and they define savings as the difference between a household's total disposable income and its total expenditure. They show that household's savings are concentrated among those with higher levels of education, which in turn, implies that richer households are better suited to leave inheritances to future generations, thus widening the inequality gap.

Considering other countries, there is also a branch of literature on the subject that focuses on explaining the relation between income inequality and consumption inequality. For example, using data from the Consumer Expenditure Survey (CE) and controlling for household income levels as well as their relative expenditure on goods, ts of Aguiar and Bils (2015) have suggested that, to a great extent, consumption inequality followed income inequality for the US between 1980 and 2007. Taking income level into account, they find that high-income households spend significantly more on luxury goods in comparison to low-income households, while expenditure on necessities do not present any substantial difference. 
Blundell and Preston (1998), at the same time, state that current income does not precisely measure the level of resources available to the household in the long run. As a result, inequality measurements based on current income may exaggerate the real position of the household within the economy. In the analysis, the authors show that consumption provides a better approximation of expected lifetime resources and so of household welfare. To this end, they use data from Britain between 1968 and 1992 and a difference-in-differences approach. In their conclusions, they explain that comparisons of consumption lead to a possible comparison of welfare between individuals but only if they are made with a cohort at a single point of time. In words, if we observe individuals' consumption over time, considering only those who share the same year of birth and the interest rate that links the periods of their life, it is possible to invert their Hicksian Demand functions and recall their utility. In summary, in this case, consumption comparisons have priority over welfare comparisons.

Following the same line of thought, Krueger and Perri (2006) argue that some variations in income are triggered by its transitory rather than its permanent components, so, current income does not give a true account of the lifetime resources available for the individual and it is therefore not a reliable indicator for welfare distribution. The authors explain this issue by considering the financial market, which does not always allow the consumer to smooth income fluctuations over time. Here, increases in income volatility will always show a smaller increase in consumption inequality, and measurements of welfare distribution will be significantly different to the welfare distribution estimated using consumption. If there is no capital income in the economy, on the other hand, risk sharing will not apply and, an increase in income inequality will always lead to an increase by the same amount in consumption inequality.

For more contributions to the debate, we also include references to Slesnick (2001), Blundell and Preston (1998), Krueger and Perri (2004), Alesina et al. (2004), Deaton and Paxson (1994) and Dagum (1990).

Income rather than consumption inequality effects on welfare have also being analyzed. Shorrocks (2004), for example, provide the conditions under which income distribution movements can lead to a correct evaluation of welfare. The author state that even though the GINI coefficient as well as the Lorenz Curve are widely accepted as inequality indices, when it comes to welfare evaluation, especially in a heterogeneous population, if they are not homogenized, the relationship cannot be precisely match, as a result, their use may bias welfare estimates. In his own complementary analysis, the author says that in order to be able to link income inequality (the GINI index) to welfare evaluations when the samples are heterogeneous, we need to deflect reported values for income by a constant scale factor so that they are homogenized.

As we can see, the discussion on which indicator should be considered for measuring welfare distribution has been always intense. Every scholar has his or her own point of view and depending on the specification they make, the analysis each presents may be valid. In this sense, as stated above, we follow the line that considers consumption as a better measurement of welfare distribution.

In the analysis we show that the growth in income inequality in Mexico is intrinsically related to changes in consumption by middle-income pseudo-households. Particularly, if we consider year and state variations in our synthetic observations, we find that a 10 percent increase in income among rich pseudo-households3, ceteris paribus, increases consumption in middle-income pseudo-households 4 by 1.57 percent.

Also, using a traditional explanation (Friedman's permanent income hypothesis), we investigate the rationality behind this result and state that when non-rich pseudo-households are exposed to higher top income levels, they expect their own income to be higher in the future as well. However, our data fails to support the hypothesis, as a result, being surrounded by households with higher levels of income, is not predictive of higher future incomes for middle-income pseudohouseholds.

Finally, in adding magnitude to the estimated effect, we perform a counterfactual analysis by asking ourselves what would have happened if the rate of growth for middleincome pseudo-households' consumption-out-of-income had increased in line with that of top-income pseudo-households. Particularly, assuming that such differences in consumption represent an increase in savings, we can show that if middleincome pseudo-households' consumption had not been exposed to a greater increase in top pseudo-household's income, the aggregate savings rate in 2006, would have been almost $20 \%$ higher, passing from 10.1 to 12.15 . Therefore, inequality is further emphasized.

The rest of the article proceeds as follows: the next section describes our data sources as well as the pseudo-panel technique we use. Our analysis, empirical results and robustness checks are explained in section 3 , and in section 4 we present our counterfactual results. Concluding comments are presented in section 5 .

\section{DATA}

The ENIGH is a cross sectional household level survey that has the purpose of providing information about the distribution and amounts of income and expenditure for Mexican households. It also includes some socio-demographic and employment characteristics of the individuals within the household. The outcomes of this survey are representative at a national level as well as separately for rural and urban areas; rural areas are those geographical areas in which the number of people is between 1 and 2,500 and urban areas are those with a population of 2,500 and more. Also, although it

\footnotetext{
${ }^{3}$ Rich pseudo-households are defined as those synthetic observations whose monthly per capita income is above the 4th quintile of income distribution in the state year cell.

${ }^{4}$ Middle-income pseudo-households are those synthetic observations whose monthly per capita income is between the 2 nd and 4 th quintile in the income distribution in the state year cell.

${ }^{5}$ In our analysis we consider the real household disposable income and net household saving rate as published by the OECD.
} 
is not representative, the survey presents information at state and municipality level.

The survey has been made every two years starting in 1989 and its reports are strictly comparable in terms of sampling frame, sampling methodology, timing, recall periods and variables of interest. Here, it is important to point out that the size sample for some years varies with respect to the rest, and in order to avoid selection problems, we consider the survey household weight.

For our purposes, this survey has been harmonized using CONEVAL's poverty analysis and it has been deflected to 2010 pesos using the consumer price index of each year. We consider households whose head was between 20 and 70 years old for the period 1992-2010.

In our analysis, however, as we are interested in the behavior of households' expenditure over time, we need to track the same individual over the period. Unfortunately, ENIGH is just a repeated cross-sectional survey that does not allow us to do so. For this reason, we need to take a preliminary step before starting the analysis and create our own panel data set with which we can follow the same observation over time.

Our panel data set is based on the construction of synthetic panel observations; that is to say, taking into account some characteristics that are assumed to be constant over time (for example, geographical areas as well as the year of birth), we created groups and followed the mean and the variance of some variables for these groups over time. The main assumption here is that the member of the group (the synthetic observation) can be followed over time.

In this technique, we are respecting the coverage of the rough data and do not exclude any state with sub-national coverage. It is important to notice that the difference in the sample of the survey in different years is due to the fact that some states wanted the sample to be representative for them.

As in every technique, the use of pseudo panels brings some pros and some cons into the analysis: for example, we can argue in its favor, that due to the fact that the sample is renewed every year, pseudo panels suffer fewer problems related to sample attrition. Also, in terms of practicality, it is well known that cross sectional data is widely available whereas panel data is not, and in that sense, constructing a pseudo panel provides an opportunity to assess specific economic issues that are mainly related to panels. Moreover, these pseudo panels are substantially more representative and frequently more extensive than normal panels.

On the other hand, is the fact that following means and variances of some variables in specific groups over time brings a trade-off between the number of cohorts and the number of observations in each cohort. Here, in order to avoid problems related to a small sample size in the regression, one would like to maximize the number of cohorts, however, this would cause the number of observations per cohort to not be large enough, and as a result, the average characteristics in the group would not be a good estimation of the real population.
Taking into account their advantages and disadvantages, pseudo panels have been widely used in the research field. For example, talking about income inequality and its dynamics over time, Fofack and Zeufak (1999), show that intrafamily transfers as well as the spatial concentration of wealth are the key determinants of income inequality in Thailand. In their work, they utilized the Socio-Economic Survey for the country from 1986 to 1996 and estimated the pseudo panel analysis by Least Square Dummy Variable (LSDV), which for instance, helped them to eliminate the cohort specific effect. Moreover, making use of the large size of their cohorts, they were able to ignore measurement error problems and avoid a crucial complication in most panels and macro econometric regressions.

In the analysis below, as mentioned previously, we limit our sample to households whose head is between 20 and 70 years old. We consider the birth cohorts for every ten years starting from 1992 and finishing in 1981; they are considered constant over time, so we are controlling for time variations in the surveys over the years. Also, apart from the birth cohort, we are considering the geographical region as fixed in the observation, which for instance, means that we are averaging groups of observations in the same state and the same locality that are in the same birth cohort. As a result, we have our own synthetic observation that can be followed over time; for simplicity, we will refer to this using the term pseudo-household.

Finally, we define our main variables, consumption and income, as follows: Consumption is equals to total household expenditure on good and services plus net imputed rent and Income, similarly, is equals to the sum of labor, assets and savings, earnings, and also the rent that would have been paid if the house were rented. Both consumption and income are normalized using CONEVAL's poverty analysis and are deflected to 2010 Mexican pesos using the consumer prices index for each year. They are considered as a monthly average per household in each birth cohort.

\section{DESCRIPTIVE}

Considering the total sample, year limitations, and the synthetic observations, we completed our pseudo panel data set with 3,767 observations divided into 10 years, 32 states and 2 localities; 11 observations are the average number of pseudo-households in the state-year cell of the pseudo panel and 370 in the year cell. Table 2 below describes these numbers; the upper panel shows the size without weight and the lower is using the average number of observations in the group considering the weight.

As we can see, the constructed pseudo-panel follows seven birth cohorts over ten periods. This compresses a total of 156,421 individual observations into 3,767 synthetic observations that constitute a sample of pseudo-households for the 32 states under consideration. Clearly, as we are considering birth cohorts as fixed, the number of observations is changing with time. 
Table 2. Sample-year and Birth Cohorts.

\begin{tabular}{|c|c|c|c|c|c|c|c|c|c|c|c|}
\hline Birth Cohort & 1992 & 1994 & 1996 & 1998 & 2000 & 2002 & 2004 & 2006 & 2008 & 2010 & Total \\
\hline $1922-1931$ & 64 & 64 & 64 & 64 & 57 & 0 & 0 & 0 & 0 & 0 & 313 \\
\hline $1932-1941$ & 64 & 64 & 64 & 64 & 64 & 64 & 64 & 64 & 63 & 62 & 637 \\
\hline $1942-1951$ & 64 & 64 & 64 & 64 & 64 & 64 & 64 & 64 & 64 & 64 & 640 \\
\hline $1952-1961$ & 64 & 64 & 64 & 64 & 64 & 64 & 64 & 64 & 64 & 64 & 640 \\
\hline $1962-1971$ & 64 & 64 & 64 & 64 & 64 & 64 & 64 & 64 & 64 & 64 & 640 \\
\hline $1972-1981$ & 35 & 59 & 64 & 64 & 64 & 64 & 64 & 64 & 64 & 64 & 606 \\
\hline $1982-1991$ & 0 & 0 & 0 & 0 & 0 & 38 & 61 & 64 & 64 & 64 & 291 \\
\hline Total & 355 & 379 & 384 & 384 & 377 & 358 & 381 & 384 & 383 & 382 & 3,767 \\
\hline $1922-1931$ & 1005 & 1104 & 801 & 389 & 185 & 0 & 0 & 0 & 0 & 0 & 3484 \\
\hline $1932-1941$ & 1489 & 1859 & 1790 & 1341 & 1213 & 1888 & 2041 & 1302 & 1217 & 629 & 14769 \\
\hline $1942-1951$ & 2040 & 2424 & 2585 & 1895 & 1689 & 2902 & 3572 & 3008 & 4201 & 3780 & 28096 \\
\hline $1952-1961$ & 2700 & 3179 & 3388 & 2588 & 2265 & 3780 & 4798 & 4313 & 6144 & 5564 & 38719 \\
\hline $1962-1971$ & 1989 & 2528 & 3224 & 2502 & 2373 & 4196 & 5844 & 5166 & 7229 & 6444 & 41495 \\
\hline $1972-1981$ & 47 & 284 & 677 & 808 & 1068 & 2292 & 3811 & 4016 & 5818 & 5752 & 24573 \\
\hline 1982-1991 & 0 & 0 & 0 & 0 & 0 & 52 & 339 & 814 & 1657 & 2423 & 5285 \\
\hline Total & 9270 & 11378 & 12465 & 9523 & 8793 & 15110 & 20405 & 18619 & 26266 & 24592 & 156421 \\
\hline
\end{tabular}

Table 3. Basic Descriptive Statistics of the Pseudo-Panel.

\begin{tabular}{|c|c|c|c|}
\hline Variable & Number of Observations (in pseudo-panel) & Mean & Standard Deviation \\
\hline$\%$ Male Children aged 0 to 16 years & 3767 & 0.2175601 & 0.1370253 \\
\hline Size of the pseudo-household & 3767 & 4.127802 & 1.024392 \\
\hline$\%$ Female members on the pseudo-household & 3767 & 0.5111087 & 0.0853358 \\
\hline Year & 3767 & 44.9712 & 15.70626 \\
\hline No education & 3767 & 0.4045452 & 0.3006649 \\
\hline Primary complete & 3767 & 0.2387243 & 0.1641744 \\
\hline Postgraduate education & 3767 & 0.0988781 & 0.1227918 \\
\hline Food poverty & 3767 & 0.1801694 & 0.1788813 \\
\hline Capacity poverty & 3767 & 0.2495315 & 0.2048138 \\
\hline Income poverty & 3767 & 0.4619879 & 0.2349693 \\
\hline
\end{tabular}

Source: See Table 2. 
Fig. (2). Geographical distribution of regions, Mexico.

\begin{tabular}{|c|c|c|c|c|c|}
\hline State Number & State Name & Region Name & State Number & State Name & Region Name \\
\hline 05 & Coahuila de Zaragoza & Northeast & 30 & Veracruz de Ignacio de la Llave & East \\
\hline 19 & Nuevo Leon & Northeast & 01 & Aguascalientes & North-Central \\
\hline 28 & Tamaulipas & Northeast & 11 & Guanajuato & North-Central \\
\hline 02 & Baja California & Northwest & 22 & Queretaro & North-Central \\
\hline 03 & Baja California Sur & Northwest & 24 & San Luis Potosi & North-Central \\
\hline 08 & Chihuahua & Northwest & 32 & Zacatecas & North-Central \\
\hline 10 & Durango & Northwest & 09 & Distrito Federal & South-Central \\
\hline 25 & Sinaloa & Northwest & 15 & Mexico & South-Central \\
\hline 26 & Sonora & Northwest & 17 & Morelos & South-Central \\
\hline 06 & Colima & West & 04 & Campeche & Southeast \\
\hline 14 & Jalisco & West & 23 & Quintana Roo & Southeast \\
\hline 16 & Michoacan de Ocampo & West & 27 & Tabasco & Southeast \\
\hline 18 & Nayarit & West & 31 & Yucatan & Southeast \\
\hline 13 & Hidalgo & East & 07 & Chiapas & Southwest \\
\hline 21 & Puebla & East & 12 & Guerrero & Southwest \\
\hline 29 & Tlaxcala & East & 20 & Oaxaca & Southwest \\
\hline
\end{tabular}

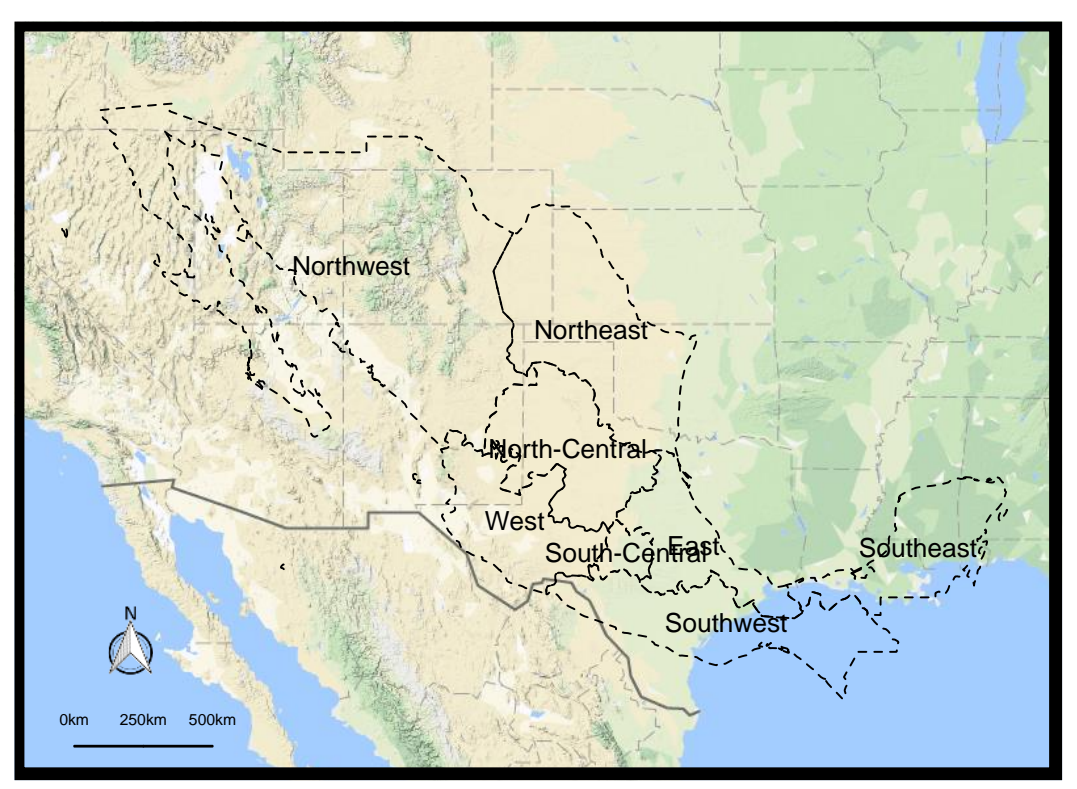

Source: Own Estimates based on ENIGHs. Table $\mathbf{3}$ provides the basic descriptive statistics of the pseudo-panel. The average per capita pseudo-household income is about $\$ 3,299$ Mexican pesos per month with a standard deviation of $\$ 2,237$, the average pseudo-household head is 45 years old and he or she has at least seven years of education. Regarding attainment, 40 percent of pseudo-households have no education or only ever started primary; 23 percent have completed primary education and started secondary; 19 per- cent have completed secondary and the remaining 16 percent have college education or any number of years of postgraduate study. The average pseudo-household is made up of 4 members and at least one of these is a male child. Also, on average, 20 percent of the pseudo-households have a female head and more than half of the members are female.

If we are talking about income distribution in Mexico, it is important to distinguish between the geographical areas we 

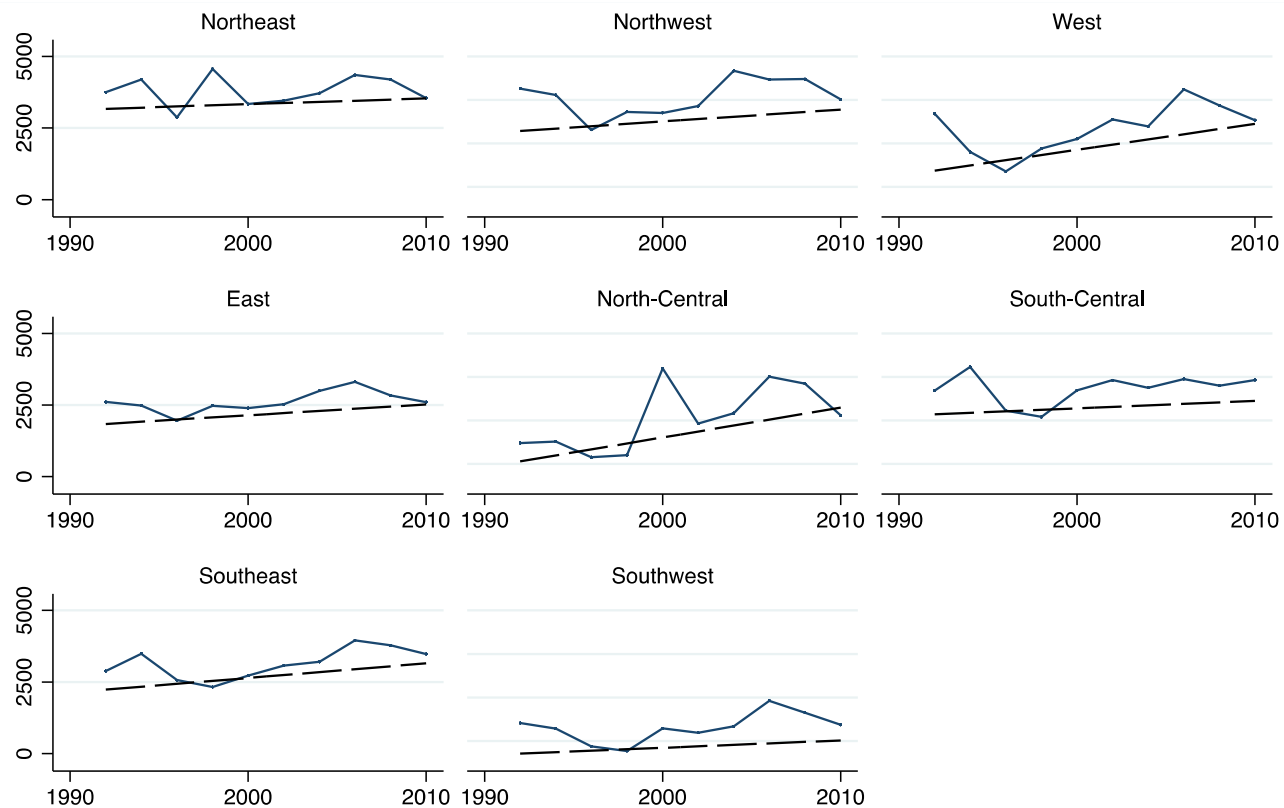

- Per capita Family Income

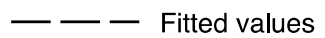

Fig. (3). Per capita Family Income Growth by Region.

Source: See Table 2.

are working with; it is well known that in different states within the country, this variable shows very drastic differences over time. On the one hand, we have Chiapas, Guerrero and Oaxaca as the poorest states with almost no growth in the previous 20 years and on the other hand, we have the capital, Mexico City (CDMX) and Morelos, as the richest states with important improvements6. Hence, before starting our analysis, it is important to define the geographical areas we are working with. To do this, we divided the country into 8 main regions taking into account their economical characteristics as well as geographical closeness. Here, we grouped states that share more or less the same economic performance (GDP evolution) and noted how they interact with each other. Fig. (2) shows our regions and the states in them.

We start our analysis by looking at the evolution of per capita family income by region. Here, it is important to notice that the indicator was constructed averaging out the synthetic observations within the region in a given year. As expected, the southwest had the lowest per capita family income in the country during the period and the regions in the northern part were those with the highest. If we look at the trend, NorthCentral shows the highest degree of improvement. Also, even though some of the regions have a very low level of income, it is clear that all of them show an improvement in this indicator. See Fig. (3).

If we consider total expenditure as a percentage of total income, Fig. (4), shows its evolution for the average Mexican pseudo-household by region. As we can see, for every region, the ratio is always very close to 0.9 and in some cases,

\footnotetext{
${ }^{6}$ See CONEVAL's analysis http://www.coneval.gob.mx/Medicion/Paginas/Evolucion-de-lasdimensiones-de-la-pobreza-1990-2010-.aspx.
}

for some years, it almost reaches 1.0. Looking at trends, the southwest is the only region that is showing an increased portion of its income going on consumption, contrary to the rest of the country. Also, considering income, the northern part of the country is performing well over time; with a relatively low level of consumption followed by a decreasing share of income spent on consumption.

Considering income distribution, we group our synthetic observations into quantiles and follow them over time as shown in Fig. (5). On the left we have the average evolution of income and on the right, average consumption as a percentage of income. As we can see, the mean per capita family income of the bottom quantile in the distribution, has experienced almost no improvement in the period, passing from 2,051 pesos per month to 2,271 (10 percent increase). The middle quantile, at the same time, has shown an interesting increase in the indicator, passing from 3,260 pesos to 3,651 (12 percent increase). Finally, the top quantile is showing a decrease of 13 percent during the period.

For consumption as a percentage of income, pseudohouseholds in the bottom quantile have spent around 92 percent of their income on consumption and those in the top quantile, around 80 percent.

In other words, this is a way of explaining the evolution of inequality in Mexico. We have, on the one hand, poor families (pseudo-households) with almost no improvements in their income level matched with an expenditure that is totally flat and almost equal to their income level, so, savings are almost equals to zero. On the other hand, we have the top quantile with a reduction in their income, but this is followed by a further reduction in their expenditure, hence, if savings are considered, the ratio gives them a better position and safeguards their future. 

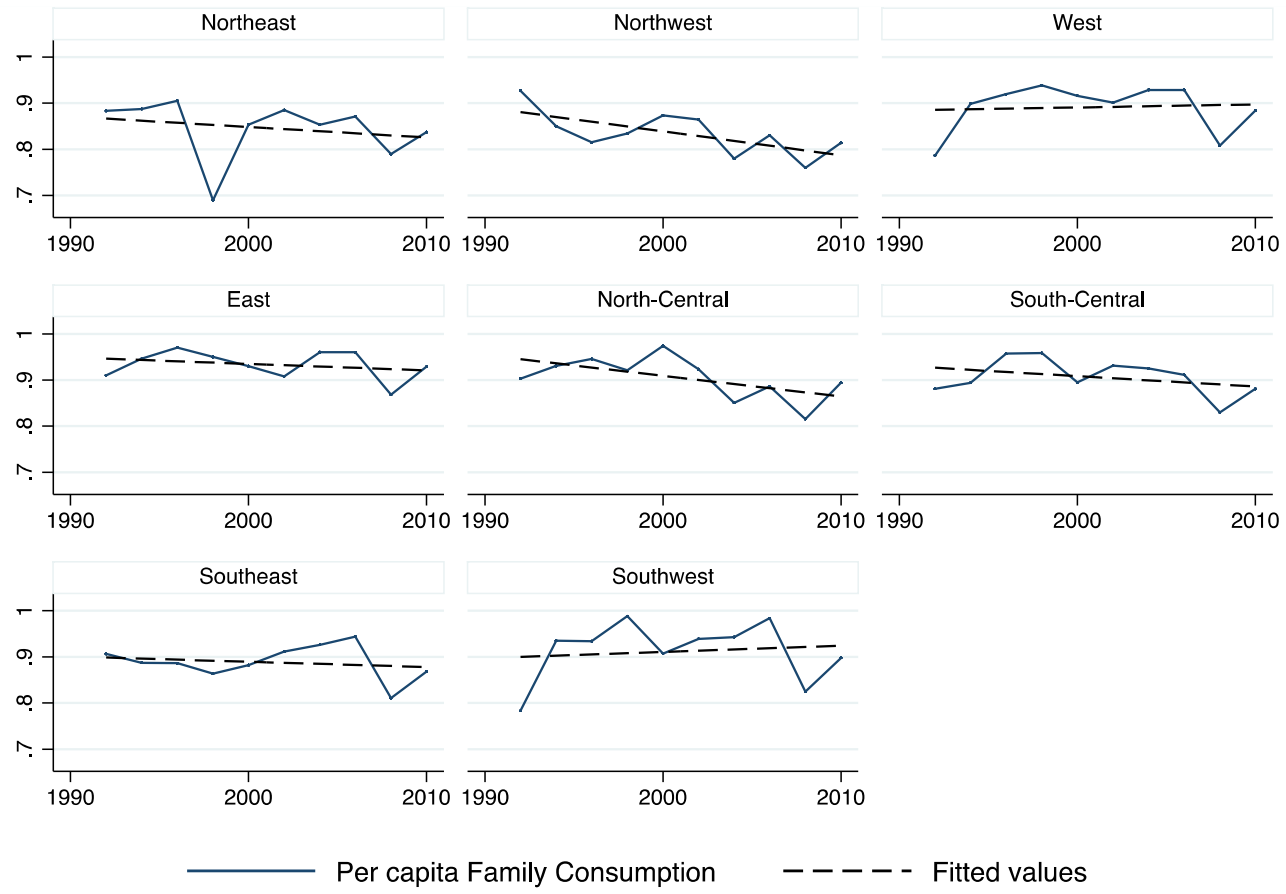

Fig. (4). Per capita Family Consumption by Region.

Source: See Table 2.
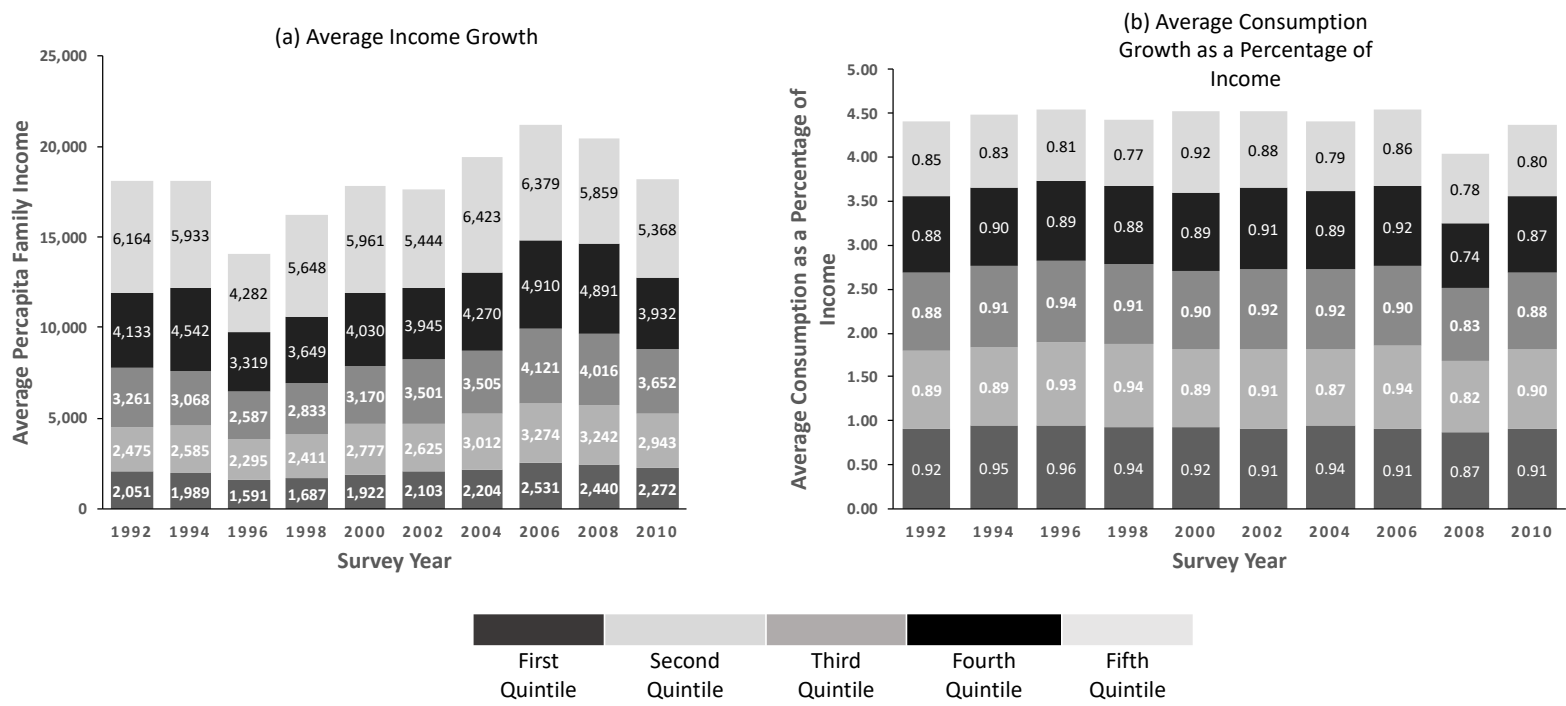

Fig. (5). Average income growth and consumption growth over time by income quantiles, Mexican pseudo households, $1992-2010$. Source: Own Estimates based on ENIGH.

\section{ANALYSIS}

Considering the empirical evidence shown above and following the idea of Bertrand and Morse (2016), we analyzed whether non-rich (the lowest quantile in the income scale) pseudo-households, being exposed to higher consumption by the rich (highest quantile in the income scale) pseudohouseholds, ceteris paribus, spend more of their disposable income.

Since our study focuses only on non-rich pseudo-households, we can drop all synthetic observations whose total income is above the 4th quantile of income distribution in their state year. Here, our main explanatory variables are the income and the consumption of rich pseudo-households.

The first estimation is a panel fixed effect regression according to the next specification:

$\log (\text { Consumption })_{i s, t}=\log (\text { consumption of rich })_{s t}+$

Pseudo-Household controls $s_{i s, t}+$ Pseudo-

Householdincomedummies $_{i}+$ Year $+\epsilon_{i s, t}$,

where $\mathrm{i}$ is the birth cohort index for the synthetic observation, $\mathrm{s}$ is the state index and $\mathrm{t}$ is the year index. Here, $\log$ (consumption of rich)st is constructed as the logarithm of 
Table 4. Relationship Between Consumption of Rich and Non-rich.

\begin{tabular}{|c|c|c|c|}
\hline & (1) & (2) & (3) \\
\hline Dependent Variable & \multicolumn{3}{|c|}{ Log (Consumption) } \\
\hline Sample & All & Middle Income & Low Income \\
\hline $\log ($ Consumption of rich $)$ & $0.179 * * *$ & $0.246^{* * *}$ & $0.0819^{* * *}$ \\
\hline & {$[0.016]$} & {$[0.022]$} & [0.029] \\
\hline \multirow[t]{2}{*}{ Constant } & $6.17 * * *$ & $5.65^{* * *}$ & $6.958 * * *$ \\
\hline & {$[0.240]$} & {$[0.324]$} & [0.406] \\
\hline Year F.E. & Yes & Yes & Yes \\
\hline Pseudo-Household income F.E. & Yes & Yes & Yes \\
\hline Pseudo-Household controls & Yes & Yes & Yes \\
\hline Observations & 2,927 & 1,744 & 1,183 \\
\hline $\mathrm{R}$-square & 0.55 & 0.513 & 0.443 \\
\hline Groups & 444 & 407 & 286 \\
\hline \multicolumn{4}{|l|}{ Standard errors in brackets } \\
\hline$* * * \mathrm{p}<0.01, * * \mathrm{p}<0.05, * \mathrm{p}<0.1$ & & & \\
\hline
\end{tabular}

the average consumption of rich pseudo-households 7 in the same state and year cell.

Differences between our synthetic observations are controlled by socio-demographical and economic factors; for example, house controls are the percentage of male children in the pseudo-household, the size of the household, the percentage of households whose head is female, the mean age of the head of the household in the synthetic observation, 5 levels of education, and types of tenure of the property. Also, we control for household income by adding income dummies according to its quantile position in the state year cell. Moreover, in order to capture aggregated changes over time, we include year dummies.

Table 4 presents the results of the estimation. In Panel A, we have the same specification against three different samples; all, middle income, and low-income pseudo-households. As the main variables are in logs, we will explain the findings in elasticities; for simplicity, we just report the main coefficients rather the whole specification.

As can be seen, in panel A, all estimations are significant at a 1 percent level and all show a positive relationship. Also, it is interesting to notice that the effect of consumption of the rich is basically concentrated among the middle-income pseudo-households (with the highest coefficient), which, for instance, is a very remarkable result considering the Mexican economy.

According to this table, being exposed to higher consumption by rich pseudo-households leads to an even higher increase in consumption for middle income pseudo house-

${ }^{7}$ By consumption of rich we mean synthetic observations whose monthly total per capita income belongs to the fifth quantile in its state year cell. holds. Here, if we consider that Mexico has shown almost no improvements in its GINI coefficient, this result suggest that pseudo-households' expenditure in the top quantile of the income distribution is pushing up that of middle-income pseudo-households, which, as mentioned before, not only pulls down non-rich pseudo-households' savings, but also aggravates inequality. ${ }^{8}$

Although our results are well explained and they match the Mexican situation, in our specification, as pointed out by Attanasio and Browning (1994), there may be identification issues; for instance, the assumption of independence between observable and unobservable effects may not hold, that is to say, it is possible that unobserved endogenous shocks may induce correlations between consumption by rich and nonrich pseudo-households, so our estimations may show some bias in the results.

Guerrero et al. (2006) demonstrate that the ENIGH shows an intrinsic measurement error; it underestimates consumption among rich households, especially for those in the top one percentile of the income distribution. In their work, in order to get a better estimation, they use variations in income of the rich rather than consumption itself. Hence, in our next specification, we regress income of the rich rather consumption.

$\log (\text { Consumption })_{i s, t}=\log (\text { income of rich })_{s t}+$
Pseudo-Household controls $_{i s, t}+$ Pseudo-

Household income dummies $_{i}+$ Year $+\epsilon_{i s, t}$,

\footnotetext{
${ }^{8}$ For findings in this line, see for example Luttmer (2005), Clark and Oswald (1996) and Easterlin (2001).
} 
Table 5. Relationship Between Income of Rich and Consumption of Non-rich.

\begin{tabular}{|c|c|c|c|}
\hline & (1) & (2) & (3) \\
\hline Dependent Variable & \multicolumn{3}{|c|}{ Log (Consumption) } \\
\hline \multirow[t]{2}{*}{ Log (income of rich) } & $0.11 * * *$ & $0.157 * * *$ & 0.0173 \\
\hline & {$[0.014]$} & {$[0.018]$} & {$[0.025]$} \\
\hline Constant & {$[0.236]$} & {$[0.320]$} & [0.395] \\
\hline Year F.E. & Yes & Yes & Yes \\
\hline Pseudo-Household income F.E. & Yes & Yes & Yes \\
\hline Groups & 444 & 407 & 286 \\
\hline \multicolumn{4}{|l|}{ Standard errors in brackets } \\
\hline$* * * \mathrm{p}<0.01, * * \mathrm{p}<0.05, * \mathrm{p}<0.1$ & & & \\
\hline
\end{tabular}

where $\log ($ income of rich) is the Log of the average income among rich pseudo-households in the same state-year cell. All other variables in the Equation (2) are the same as those defined in Equation (1). Results are presented in Table $\mathbf{5}$ and the specification follows that of Table $\mathbf{4}$ with three different sample sizes.

As we can see, both tables (Table $\mathbf{4}$ and 5) are quite consistent; we have a positive and significant association between the variables and the impact is mainly concentrated in middle-income pseudo-households. As a result, the analysis holds.

Going deeper into the estimation, and as a robustness check, in Table 6, we present the results of the instrumental variables approach applied to the specification above. Here, as stated above, $\log$ (consumption of rich) is instrumented with its own income; we use $\log$ (income of rich) and $\log (4$ th quantile income) as instruments.

As we can see, these instruments are strong predictors of our focal variable; the first stage F-statistic is 187.97 (column 1 of the table). Also, considering columns 2 to 4 , our main estimation in Equation (1) reflects a substantial robustness; with a positive association between the variables and moreover, a very clear concentration in middle income pseudohouseholds. Here, it is interesting to note how this elasticity increases, passing from 0.246 (Column 2, Table 4) to 0.367 (Column 3, Table 6), showing a 50 percent increment.

This result reinforces our findings; considering consumption of the rich, estimated through its own income so that it is being controlled for its measurement error, we see a more realistic effect over non-rich pseudo-households' consumption. It is important to point out, though, that we are considering total pseudo-household expenditure, hence, it is easy to argue that before we were omitting some positively correlat- ed shocks to tastes that are somehow similar between rich and non-rich pseudo-households, especially those in the third, fourth and fifth quantiles of income distribution.

Summing up, we just showed that there is clear a relationship between consumption of the rich and that of the nonrich pseudo-households in the country. Also, according to Table 4, we know that a one percent increase in $\log$ (Consumption of rich), ceteris paribus, increases nonrich consumption by 0.246 percent. Furthermore, as explained before, we conclude that this behavior is pushing the economy to a higher level of inequality, with a pauperization of the poor and a higher concentration of welfare among rich pseudo-households. Nevertheless, is there some rationality behind this behavior? What is pushing non-rich pseudohouseholds to spend more of their income when the rich pseudo-households spend more? Is there a status-level explanation to this? Or is it just casual?

Thus, in trying to find an explanation, we say that when nonrich pseudo-households are surrounded by households with higher levels of income, they expect their own income to be higher in the future. Equation (3) below presents a panel-data estimation that test our hypotheses

$$
\begin{aligned}
& \log (\text { FutureIncome })_{i s, t}=\log (\text { income of rich })_{s t}+ \\
& \text { Log }(\text { Cirrent income of rich })_{i, s t} \\
& \text { Pseudo-Household controls }{ }_{i s, t}+\text { Year }+\in_{i s, t},
\end{aligned}
$$

$\log$ (Future income) is expressed as the log of the pseudohousehold's income in period $\mathrm{t}+1, \mathrm{t}+2$ and $\mathrm{t}+4, \log$ (Income of rich), is as before, the Log of the average income among rich pseudo-households in the same state-year cell. Time varying pseudo-household controls include a quadratic for the age of the pseudo-household's head, the percentage of occupier owned households in the synthetic observation, the 
Table 6. Relationship Between Income of Rich and Consumption of Non-rich, IV Estimates.

\begin{tabular}{|c|c|c|c|c|}
\hline & (1) & (2) & (3) & (4) \\
\hline & First Stage & & & \\
\hline Dependent Variable & Regression & \multicolumn{3}{|c|}{ Log (Consumption) } \\
\hline & for Colum (2) and (5) & & & \\
\hline & $\log ($ Consumption of rich $)$ & & & \\
\hline Sample & All & All & Middle Income & Low Income \\
\hline \multirow[t]{2}{*}{ Log (income of rich) } & 0.5 & & & \\
\hline & {$[0.014]^{* * *}$} & & & \\
\hline \multirow[t]{2}{*}{$\log (4$ th Quantile Income $)$} & 0.28 & & & \\
\hline & {$[0.019]^{* * *}$} & & & \\
\hline \multirow[t]{2}{*}{$\log$ (Consumption of rich) } & & $0.239 * * *$ & $0.367 * * *$ & 0.0559 \\
\hline & & {$[0.023]$} & {$[0.031]$} & {$[0.040]$} \\
\hline \multirow[t]{2}{*}{ Constant } & & $4.928 * * *$ & $3.968 * * *$ & $5.721 * * *$ \\
\hline & & {$[0.448]$} & {$[0.558]$} & [0.943] \\
\hline Year F.E. & Yes & Yes & Yes & Yes \\
\hline Pseudo-Household income F.E. & Yes & Yes & Yes & Yes \\
\hline Pseudo-Household control & Yes & Yes & Yes & Yes \\
\hline Observations & 2888 & 2,888 & 1,729 & 1,159 \\
\hline Groups & 443 & & & \\
\hline $\mathrm{R}$-square & 0.6951 & & & \\
\hline Firs Stage F statistics & 187.97 & & & \\
\hline \multicolumn{5}{|l|}{ Standard errors in brackets } \\
\hline$* * * \mathrm{p}<0.01, * * \mathrm{p}<0.05, * \mathrm{p}<0.1\}$ & & & & \\
\hline
\end{tabular}

percentage of male children, the size of the pseudohousehold, dummies for education and the percentage of female pseudo-household heads. Also, in controlling for state and year variations, we cluster standard error at the state level. Moreover, for robustness in the specification, we include $\log (3 \mathrm{rd}$ quantile income $)$ and $\log (2$ nd quantile income $)$ as the pseudo-household's income controls.

Results are presented in Table 7. We estimate three different regressions for each dependent variable and the main regressor is $\log$ (income of rich)9. As we can see, most of the coefficients are not statistically different to zero, so, we fail to find any relationship. It is important to notice that this pattern holds for any different future period and any inclusion of pseudo-household fixed effects, also, it is robust and moreover, the relationship is not only not significant but in most of the cases it is negative.

${ }^{9}$ As before, non-rich pseudo-households (the dependent variable) are those below the fourth quantile in the income distribution in the state year cell.

\section{COUNTERFACTUAL ANALYSIS}

In this section and with the aim of adding magnitude to the effects estimated in Equation 2 and Table 5, we present a counterfactual analysis. That is to say, we analyze what would have happened if the growth rate of middle-income pseudo-households' consumption-out-of-income had increased at the same pace as that of top-income pseudohouseholds. With this in mind, we measure the differences in consumption levels over time and particularly, their respective translation into savings.

Our analysis computes the decrease in $\log$ (Consumption) under the assumption that $\log$ (income of rich) has grown at the same rate as $\log (3 \mathrm{rd}$ quantile income). In our calculation, we use Table 5's estimation (Panel A, Column 2) of the change in $\log$ (consumption) for middle-income pseudohouseholds to $\log$ (income of rich). Results are presented in Table $\mathbf{8}$ and the estimation is carried out for two years of analysis (2002 and 2006) and two variables; differences in $\log$ consumption and consumption itself. For 2002, we estimate that middle-income pseudo-households' log consumption would have been 0.6 percent lower under counterfactual, and 1.2 percent in 2006 (Column 2). 
Table 7. Relationship Between Rich and Non-rich Future Income.

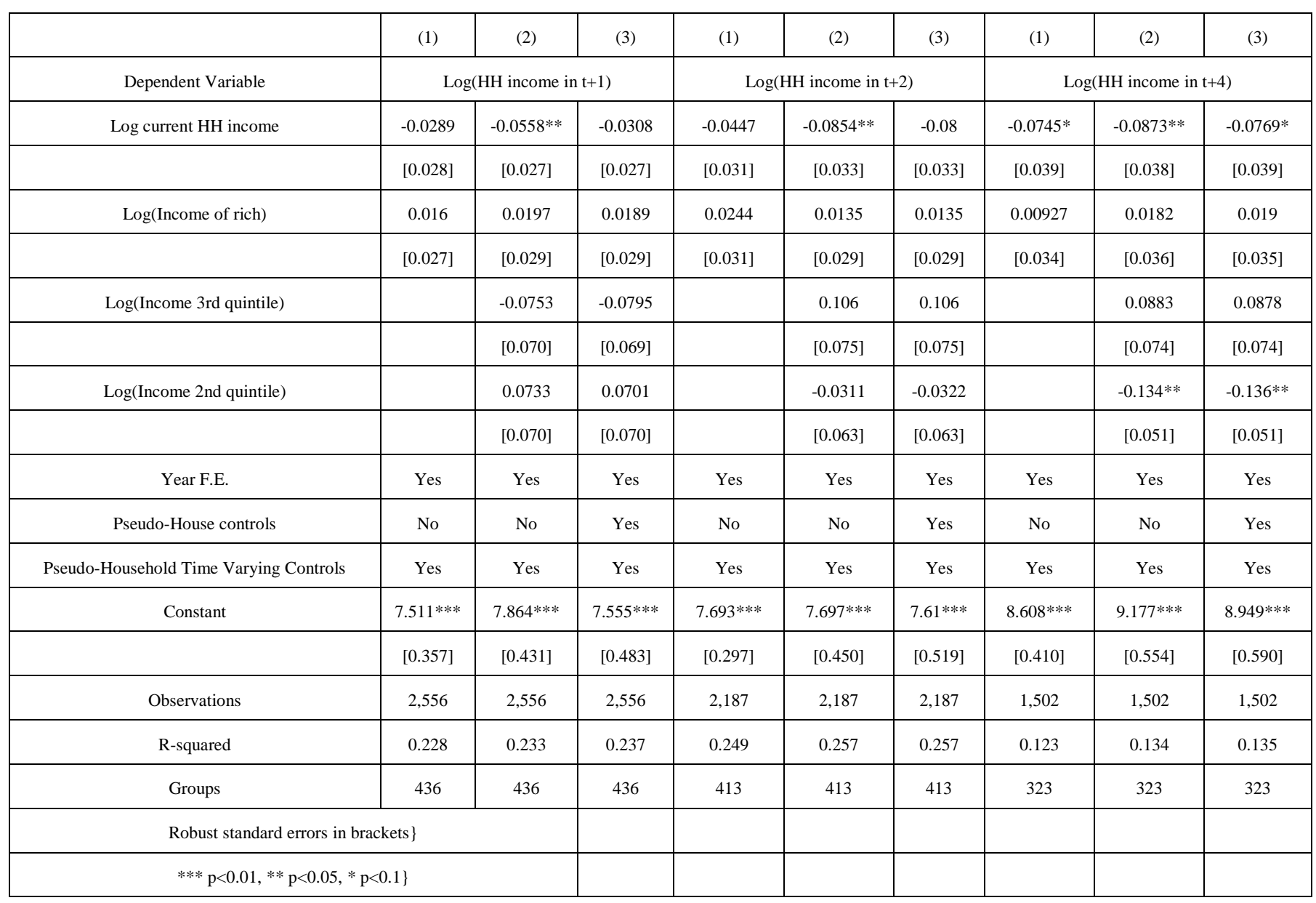

For columns 3 and 5, we consider the real household disposable income and net household savings rate as publish by the OECD. ${ }^{10}$ Also, additional savings under counterfactual (column 4), for each year, are calculated as the multiplication of the reduction in consumption we got in the previous paragraph, times the proportion of middle-income households withing the country ${ }^{1112}$. Finally, in column 6 , we report the additional savings rate under counterfactual as an aggregation of the additional savings plus the current savings divided by net household disposable income.

We estimate that the pseudo-households' savings rate in 2002, would have been 11.6 percent rather than 11.4 percent (an increase of 1.75 percent) and in 2006 it would have been 12.1 rather than 10.1 (an increase of 19.8 percent).

Therefore, as we can see, the economic implications of our analysis are not trivial at all; we are showing that if middleincome pseudo-households' consumption had not been exposed to a higher increase in top pseudo-households' income, their savings rate could have been almost 20 percent higher

\footnotetext{
${ }^{10}$ The change in consumption is reported in 2010 pesos as the average pseudo-household's income in the same quantile for a given year.

${ }^{11}$ This estimation is based on the numbers presented for Lopez-Calva and Ortiz-Juarez (2011) and the INEGI.

${ }^{12}$ For 2002 we consider middle-income households as 38.4 percent of the total and in 2006 the number went up to 40.41 percent.
}

in 2016. As a result, under some reasonable assumptions, income and consumption inequality levels would have been lower and, as pointed out by Birdsall et al. (1996), economic growth could have been higher.

In conclusion, no matter what the specification is, we fail to find support for the hypothesis we stated before, in other words, ceteris paribus, being exposed to households with higher levels of income in a state-year cell, is not a sufficient condition to ensure higher future income in that state for the non-rich pseudo-households.

\section{CONCLUDING REMARKS}

In this paper we follow Bertrand and Morse's ideas of trickle-down consumption and explain income inequality in Mexico. We take consumption variations to be a response to income variations and we exploit those variations at the upper quantile of the income distribution withing the Country.

In the analysis, due to data limitations, we create our own micro panel data set by averaging groups of observations that share the same characteristics into one synthetic observation that can be followed over time; this synthetic observation is called pseudo-household. The rough data for the analysis is taken from the National Survey on Household Income and Expenditure (ENIGH) for the period 1992-2010. 
Table 8. Counterfactual Analysis.

\begin{tabular}{|c|c|c|c|c|c|c|}
\hline & (1) & (2) & (3) & (4) & (5) & (6) \\
\hline & \multicolumn{5}{|c|}{ Counterfactual Analysis for Colum 2 Table 5, Panel A } & \\
\hline & Change in & Change in & & Additional & Net & Net household \\
\hline \multirow[t]{3}{*}{ Variable } & Log(Consumption) & Consumption & Net & Savings & household & saving rate \\
\hline & under & under & household & under & saving & under \\
\hline & counterfactual & counterfactual & saving & Counterfactual & rate & Counterfactual \\
\hline 2002 & -0.006 & -886.586 & 699.989 & 7.581 & 0.114 & 0.116 \\
\hline 2006 & -0.012 & -14321.484 & 706.936 & 143.546 & 0.101 & 0.121 \\
\hline
\end{tabular}

Source: Own calculation based on OECD (for Net household disposable income and Savings rate) and INEGI reports (for the number of middle-income households).

Notes:

(1). Reports in Table are estimations of changes in middle-income household's consumption as well as personal savings rate for the Country.

(2). This counterfactual analysis assumes that income of rich grew at the same rate as that of middle-income households. See text for details.

(3). Columns 3 and 4 are reported in billions.

According to our results, middle-income pseudo-households that are exposed to an increase in top-income pseudohouseholds' consumption appear to spend a higher proportion of their income. In particular, this elasticity is 0.246 percent when exposed to an increase in consumption and 0.157 when exposed to an increase in income. In fact, if middle-income pseudo-households' consumption had not been exposed to a higher increase in top pseudo-households' income, their savings rate could have been almost 20 percent higher and as a result, under some reasonable assumptions, income and consumption inequality levels would have been lower.

Also, in explaining the rationality behind such behavior, we found that being exposed to higher top income levels in a state-year cell today, is not a sufficient condition to ensure higher future income in that state-year cell for the non-rich pseudo-households. Thus, the overconsumption by non-rich pseudo-households is not fully understood yet and, in future work, it will be worth complementing this study, by, for example, focusing on the consumption of different goods rather than on consumption in general.

\section{CONFLICT OF INTEREST STATEMENT}

The authors declare that they have no conflict of interest.

\section{REFERENCES}

Aguiar, M., and Bils, M. (2015). Has consumption inequality mirrored income inequality?. American Economic Review, 105(9), 2725-56.

Alesina, A., R. Di Tella, and R. MacCulloch (2004). Inequality and happiness: are Europeans and Americans different? Journal of Public Economics 88(9), 2009-2042.

Attanasio, O. and M. Browning (1994). Testing the life cycle model of consumption: What can we learn from micro and macro data. Investigaciones Económicas 18(3), 433-463.
Attanasio, O. and M. Székely (1998). Household savings and income distribution in Mexico. Inter-American Development Bank, Working Paper 390

Bertrand, M. and A. Morse (2016). Trickle-down consumption. Review of Economics and Statistics 98(5), 863-879.

Birdsall, N., T. Pinckney, and R. Sabot (1996). Why low inequality spurs growth: Savings and investment by the poor.

Blundell, R. and I. Preston (1998). Consumption inequality and income uncertainty. The Quarterly Journal of Economics 113(2), 603-640.

Clark, A. E. and A. J. Oswald (1996). Satisfaction and comparison income. Journal of Public Economics 61(3), 359-381.

Dagum, C. (1990). On the relationship between income inequality measures and social welfare functions. Journal of Econometrics 43 (1), 91102.

Deaton, A. and C. Paxson (1994). Intertemporal choice and inequality. Journal of political economy 102(3), 437-467.

Easterlin, R. A. (2001). Income and happiness: Towards a unified theory. The Economic Journal 111(473), 465-484.

Fofack, H. and A. Zeufak (1999). Dynamics of income inequality in Thailand: Evidence from household pseudo-panel data. The World Bank, Washington DC.

Frank, R. H., A. S. Levine, O. Dijk, et al. (2014). Expenditure cascades. Review of Behavioral Economics 1(1-2), 55-73.

Guerrero, I., L. F. López-Calva, and M. Walton (2006). The inequality trap and its links to low growth in México. Stanford Center for International Development. Working Paper (298).

Krueger, D. and F. Perri (2004). On the welfare consequences of the increase in inequality in the united states. In NBER Macroeconomics Annual 2003, Volume 18, pp. 83-138. The MIT Press.

Krueger, D. and F. Perri (2006). Does income inequality lead to consumption inequality? evidence and theory. The Review of Economic Studies 73 (1), 163-193.

Lopez-Calva, L. F. and E. Ortiz-Juarez (2011). A vulnerability approach to the definition of the middle class. The Journal of Economic Inequality, 1-25. 
Luttmer, E. F. (2005). Neighbors as negatives: Relative earnings and wellbeing. The Quarterly Journal of Economics 120(3), 963-1002.

Shorrocks, A. (2004). Inequality and welfare evaluation of heterogeneous income distributions. The Journal of Economic Inequality 2 (3), $193-218$.

Received: Nov 30, 2020

Revised: Dec 15, 2020
Slesnick, D. T. (2001). Consumption and social welfare: Living standards and their distribution in the United States. Cambridge University Press.

Copyright $\odot$ 2020- All Rights Reserved

This is an open-access article. 